Document downloaded from:

http://hdl.handle.net/10251/62129

This paper must be cited as:

Serrano, A.; Espinach, FX.; Tresserras, J.; Rey Tormos, RMD.; Pellicer, N.; Mutje Pujol, P. (2014). Macro and micromechanics analysis of short fiber composites stiffness: The case of old newspaper fibers-polypropylene composites. Materials and Design. 55:319-324. doi:10.1016/j.matdes.2013.10.011.

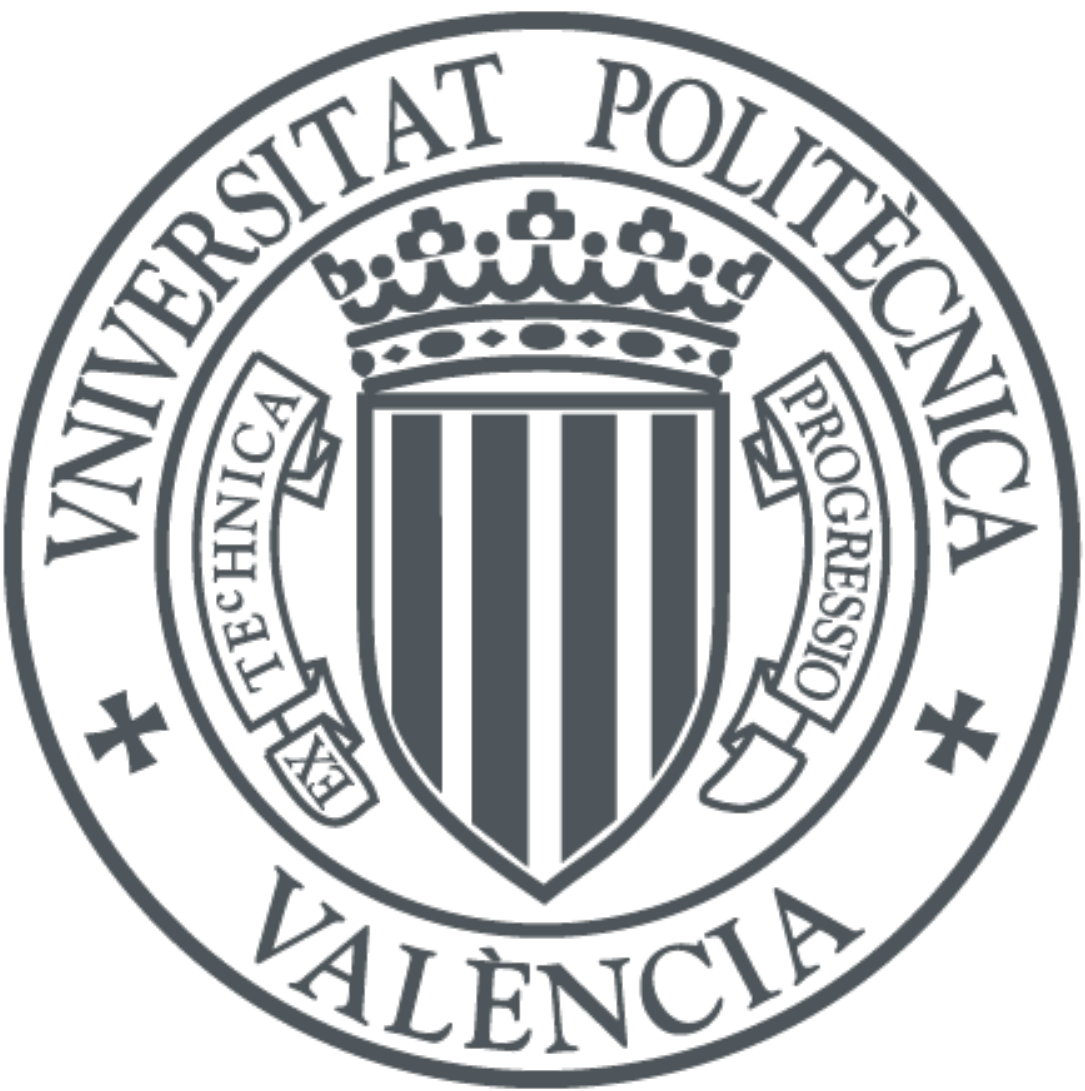

The final publication is available at

http://dx.doi.org/10.1016/j.matdes.2013.10.011

Copyright Elsevier

Additional Information 


\section{Macro and micromechanics analysis of short fiber composites stiffness: the case of old newspaper fibers-polypropylene composites}

Serrano, $A^{b}$., Espinach, F. $X^{\star a}$., Tresserras, $J^{a}$., del Rey, $R^{c}$., Pellicer, $N^{d}$., Mutje, $P^{b}$.

*Escola Politecnica Superior. Avda. Lluis Santalo, s/n, 17071 Girona, Spain. Francisco.espinach@udg.edu, TIf. +34 972418 920, FAX +34 972418399

aDesign, Development and Product Innovation, Dpt. Of Organization, Business Management and Product Design, (Spain).

baboratory of Paper Engineering and Polymer Materials, Dpt. Of Chemical Engineering, University of Girona (Spain)

'Instituto para la Gestión Integrada de las Zonas Costeras. IGIC. Escola Politècnica Superior de Gandia.Universitat Politècnica de València (Spain)

${ }^{\mathrm{d}}$ Dpt. Of Chemical Engineering, University of Girona (Spain)

\section{Abstract}

Stiffness is one of the most relevant characteristics of composite materials. Natural wood fibers have demonstrated their ability to increase the Young's moduli of composite materials, and old newspapers are a potential source of reinforcing fibers for composite materials. There are some micromechanic models to predict the Young's modulus of composite materials, and one of the input data is the intrinsic modulus of their fibers. This intrinsic modulus is a value which is difficult or impossible to measure in the case of wood fibers, due to their measures. This paper evaluates the stiffening abilities of old newspaper fibers and the possibility to back calculate the value of the intrinsic Young's Modulus by means of 
micromechanic models. Different percentages of old newspaper fibers were compounded with polypropylene (PP). Micromechanics of the fibers were obtained using Hirsch model, Cox-Krenchel's model, Tsai-Pagano model and Halpin-Tsai equations. The most important results were the average intrinsic Young's modulus of the fibers, the mean orientation angle and the mean modulus efficiency factor.

Keywords: Natural fibers, Recycling, Mechanical properties, Composites.

\section{Introduction}

In recent years, wood fiber and natural fibers have gained a significant interest as a reinforcing material for commercial thermoplastics [1-6]. Some advantages of natural fibers as opposed to other reinforcing materials are their high availability, their biodegradability, and their relative low cost and density. Newspapers usually contain a high percentage of recycled fibers from wood and mineral fillers, and therefore, used newspapers become a potential source of reinforcing fibers [7-11]. In spite of their advantages, the use of cellulose fibers from newspaper as reinforcement elements for thermoplastics has not been extensively investigated [7].

Virgin wood fibers and cellulosic fibers from recycled papers, when used as reinforcement with the adequate coupling agents, are able to increase both the elastic moduli and the strength of the composite materials [12-19]. The strength of natural fiber reinforced composites is highly influenced by the incompatibility between the hydrophilic fibers and the hydrophobic polymers. The most common way to improve the interface is the addition of coupling agents $[10,17,19-22]$. However that treatment slightly affects the stiffness of the natural fiber reinforced composites.

For structural and semi structural applications, the most relevant properties are probably stiffness and dimensional stability [23]. Lopez et al. [2] found a 1.09 ratio between the Young modulus of $30 \%$ glass fiber (GF)-polypropylene and $50 \%$ stone groundwood mechanical 
pulp - polypropylene composites. Old newspaper fibers (ONF), due to their good specific properties, could achieve their own space of competitiveness in semi structural applications. [24].

In order to predict the elastic properties of the composite materials it is necessary to know the intrinsic Young's modulus of the fibers, defined as the average slope in the stress-strain curve in the strain interval from 0 to $0.3 \%$ [23]. Unfortunately, due to their characteristic morphology, the experimental evaluation of the Young's moduli of ONF is costly and difficult, and sometimes impossible. The mechanical properties of composites can also be predicted by means of micromechanical models. The models are based on different assumptions and experimental data. The most common one's are based on the rule of mixtures (ROM) and can be used to back calculate the intrinsic properties of the reinforcing fibers $[2,25,26]$. In the case of short fiber semi-aligned composites, the most commonly used models to predict the Young's modulus or the intrinsic Young's modulus, are modified rules of mixtures (mROM) [27], Hirsch model [28], and Halpin-Tsai equations with Tsai-Pagano methods [2, 29-31].

In this work composites from polypropylene (PP) and old newspaper fibers (ONF) were formulated, prepared and tested to mechanically characterize its Young's moduli. This study complements the analysis of the tensile strength of these composites carried out previously [8], and is focused on the stiffness of the composites. The moduli were analyzed from a macromechanical point of view, and their micromechanical aspects were evaluated. The values of the intrinsic Young's moduli of the fibers were obtained by means of Hirsch model [28], and also by means of Halpin-Tsai equations with Tsai-Pagano methods [29-31] and then compared, to assess the influence of the aspect ratio of the fibers on the values. By means of Cox-Krenchel equations [32, 33] were studied the length efficiency factors, and also were deduced the fiber orientation factors. The mean orientation angles of the fibers, assuming a rectangular distribution of the fibers inside the matrix (square packing), were also computed. 


\section{Materials and methods}

\subsection{Materials}

Old newspaper, containing $85 \%$ of wood recycled fibers and $15 \%$ of calcium carbonate mineral filler, was supplied by Punt Diari, printed by Rotimprès (Spain).

The composites were prepared using homopolymer polypropylene, (PP) (Isplen PP090 G2M) which was provided by Repsol -YPF (Tarragona, Spain) as the polymer matrix. Polypropylene functionalized with maleic anhydride (MAH-PP) (Epolene G3015), which was acquired from Eastman Chemical Products (Spain) and used as coupling agent. Diethyleneglycol dimethyl ether (diglyme) was supplied by Clariant and was used as dispersing agent. Decahydronaphthalene (decalin), supplied by Fisher Scientific, was used to dissolve the PP matrix in the fiber extraction from composites process.

\subsection{Disintegration of the old newspaper}

The old newspapers were cut into pieces of $10 \times 10 \mathrm{~cm}$, approximately and were soaked in water for 3 hours at $50^{\circ} \mathrm{C}$, with a $1 \%$ of $\mathrm{NaOH}$, in a heated stainless steel vessel. Then the cuts were submitted to the disintegration process by means of a pilot scale pulper (Pucel Cell from Metrotech, France) equipped with an helicoidal rotor, deflectors, and with an effective volume of $20 \mathrm{l}$. The disintegration was performed at $20 \mathrm{rev} / \mathrm{s}$ rotor speed, at a temperature of $50^{\circ} \mathrm{C}$, and $10 \%$ consistency. Afterwards the pulped material was filtered and oven dried at $80^{\circ} \mathrm{C}$. Following, the fibers were dispersed in a water-diglyme (1:3) mixture. The use of diglyme in the previous step limits the formation of hydrogen bonds between the cellulosic fibers [34]. A $5 \%$ of the $\mathrm{CaCO}_{3}$ was lost during the disintegration and individualization processes.

\subsection{Composite preparation.}

PP composite materials comprising 20 to $50 \mathrm{wt} \%$ of ONF were compounded by means of a Brabender internal mixing machine. The mixing process was performed at $80 \mathrm{rpm}$ rotor 
speed and a temperature of $180^{\circ} \mathrm{C}$ for 10 minutes. The obtained blends were ground by means of a knives mill, dried and stored for at least 24 hours before processing.

\subsection{Composite processing.}

The samples for the tensile test were produced with a steel mould in an injection-molding machine (Meteor 40, Mateu \& Solé). Ten test specimens from each obtained composite blend were used for the experiment. The processing temperatures were 175,175 , and 190 ${ }^{\circ} \mathrm{C}$ (the machine has three heating areas), the last corresponding to the injection nozzle. First and second pressures were 120 and $37.5 \mathrm{kgf} / \mathrm{cm}^{2}$, respectively. Standard composite specimen samples (approx. $160 \times 13.3 \times 3.2 \mathrm{~mm}$ ) were obtained and used to measure the tensile properties.

\subsection{Mechanical characterization.}

The specimens were stored in a Dycometal conditioning chamber at $23^{\circ} \mathrm{C}$ and $50 \%$ relative humidity for $48 \mathrm{~h}$, in agreement with the ASTM: D638 standard [35]. Afterwards, composites were assayed in a Universal testing machine (Instron ${ }^{\mathrm{TM}}$ 1122), fitted with a $5 \mathrm{kN}$ load cell and operating at a rate of $2 \mathrm{~mm} / \mathrm{min}$. Young's modulus was analyzed using extensometer in dog-bone specimens. Results were obtained from the average of at least 5 samples.

\subsection{Fiber extraction from composites}

Reinforcing fibers were extracted from composites by matrix solubilization using a Soxhlet apparatus and decalin as solvent. Small pieces of composites were cut and placed inside a cellulose filter and set into the Soxhelt equipment. A small cotton tab was used to prevent the fibers from getting out of the filtering tube. The fiber extraction was completed after $24 \mathrm{~h}$. Once the fibers were extracted, they were rinsed with acetone and then with distilled water in order to remove the solvent residue. Finally the fibers were dried in an oven at $105^{\circ} \mathrm{C}$ for 24 h. 


\subsection{Determination of the fiber length and diameter}

Fiber's length distribution and diameter of the extracted fibers were characterized by means of a MorFi Compact (Morfological fiber analyser), from Techpap SAS, (France). A minimum of two samples were analyzed.

\subsection{Density measurement}

The density measurement of the composite $\left(\rho^{c}\right)$ was carried out using a pycnometer. Distilled water at $23^{\circ} \mathrm{C}$ was used as a reference liquid. The ISO 1183-1 [36] standard was respected throughout this experiment. The density of the fiber $\left(\rho^{f}\right)$ was obtained from: $\rho^{C}=w^{C} /\left(\left(w^{m} / \rho^{m}\right)+\left(w^{f} / \rho^{f}\right)\right)$, where $w^{c}, w^{m}$, and $w^{f}$ are the loads in weight of the composite, matrix, and fiber and $\rho^{m}$ is the density of the matrix.

\section{9 eqYoung's modulus modeling approaches}

The value of the tensile modulus of natural fibers is very variable [37-40]. In some cases, as for example lignocellulosic fibers from wood or from agro-forestry wastes (corn stalks, rape stalks, hemp core fibers...), the experimental measurement of their elastic modulus is practically impossible. However the intrinsic tensile or flexural modulus of the fibers is a key factor to predict the tenilel or flexural modulus for the composite materials. Therefore, in these cases, the best choice is to use mathematical models to estimate the value of the intrinsic elastic modulus of the reinforcements from the tensional or flexural modulus of the composite. Hirsch model (Eq.1) [28], is a valid tool to estimate the intrinsic modulus of the reinforcement $\left(E_{t}^{f}\right)[41-43]$.

$$
E_{t}^{C}=\beta \cdot\left(E_{t}^{f} V^{f}+E_{t}^{m}\left(1-V^{f}\right)\right)+(1-\beta) \frac{E_{t}^{f} \cdot E_{t}^{m}}{E_{t}^{m} \cdot V^{f}+E_{t}^{f}\left(1-V^{f}\right)}
$$

Where $E_{t}^{C}, E_{t}^{f}, E_{t}^{m}$ are the elastic modulus of the composite, the reinforcement, and the matrix respectively; and $V^{f}$ is the volume fraction of the reinforcement; and $\beta$ is a parameter which determines the stress transfer between the fiber and the matrix. It has been reported 
that the value of $\beta$ is mainly influenced by the fibers orientation and the stress concentration effects at the end of the fibers [44]. A value of $\beta=0.4$ has been reported to reproduce adequately results obtained experimentally for natural fiber composites [41, 42]

The inclusion of the value of $E_{t}^{f}$ in the modified rule of mixtures mROM (Eq.2) [27], enabled calculation of the modulus efficiency factor $\left(\eta_{e}\right)$.

$E_{t}^{C}=\eta_{e} \cdot E_{t}^{f} \cdot V^{f}+E_{t}^{m} \cdot\left(1-V^{f}\right)$

To determine the global contribution of the reinforcements to the Young's moduli of the composite materials, as a function of the fiber content, a fiber tensile modulus factor (FTMF) [2] was defined by isolating the contribution of the fibers to the Young's modulus of the composite in the modified rule of mixtures (Eq.2). The FTMF was defined as:

$F T M F=\frac{E_{t}^{C}-\left(1-V^{f}\right) \cdot E_{t}^{m}}{V^{f}}=\eta_{e} E_{t}^{f}$

FTMF can be calculated directly from the experimental data, and its value is invariant with respect to the fiber volume fraction. Thus its value depends mainly on the characteristics of the fiber and the matrix, and slightly in their interface [2]. The efficiency factor corrects the contribution of semi aligned fibers, and can be expressed as the product of the orientation factor and the length efficiency factor $\left(\eta_{e}=\eta_{0} \cdot \eta_{l}\right)[43,45]$.

The length efficiency factor was calculated according to Cox-Krenchel's model (Eq. 4, 5) [33]:

$\eta_{l}=1-\frac{\tanh \left(\beta \cdot l^{f} / 2\right)}{\left(\beta \cdot l^{f} / 2\right)}$

With

$$
\beta=\frac{1}{r} \sqrt{\frac{E_{t}^{m}}{E_{t}^{f} \cdot(1-v) \operatorname{Ln} \sqrt{\pi / 4 \cdot V^{f}}}}
$$


where this $\beta$ is the coefficient of stress concentration rate at the end of the fibers, $r$ is the fiber mean radius, $I^{f}$ is the fiber's weighed length, $r$ is the mean radius of the ONF, and $v$ is the Poisson's ratio of the matrix, assumed to be 0.36 [22]. The orientation factor $\eta_{o}$ was obtained from $\eta_{o}=\eta_{l} / \eta_{e}$.

Fukuda and Kawata [46] studied the tensile modulus of short fiber reinforced thermoplastics, assuming a rectangular distribution of the fibers inside the matrix (square packing). The orientation efficiency factor can be obtained from Eq. (6).

$$
\eta_{o}=\frac{\sin (\alpha)}{\alpha}\left(\frac{3-v}{4} \frac{\sin (\alpha)}{\alpha}+\frac{1+v}{4} \frac{\sin (3 \alpha)}{3 \alpha}\right)
$$

With the known values for $\eta_{0}$ it was possible to solve the equation, finding the mean orientation angle $(\alpha)$.

It is accepted that the aspect ratio (ratio between fiber, length and diameter) has a role in the final mechanical characteristics of composite materials [18, 42, 47]. While Hirsch model doesn't explicitly incorporate the aspect ratio in the equations, Tsai-Pagano model (Eq. 7) and Halpin-Tsai equations [30, 31] do, and they were also used to predict the intrinsic tensile modulus of the fibers. The stiffness in the fiber direction is given by:

$$
E_{t}^{C}=\frac{3}{8} E^{11}+\frac{5}{8} E^{22}
$$

Here, $E^{11}$ and $E^{22}$ are the longitudinal and transversal elastic modulus, calculated by the Halpin -Tsai equations [43]:

$$
\begin{aligned}
& E^{11}=\frac{1+2\left(l^{f} / d^{f}\right) \eta_{l} V^{f}}{1-\eta_{l} V^{f}} E_{t}^{m} \\
& E^{22}=\frac{1+2 \cdot \eta_{t} V^{f}}{1-\eta_{t} V^{f}} E_{t}^{m}
\end{aligned}
$$

Being the parameters $\eta_{l}$ and $\eta_{t}$ given by: 
$\eta_{l}=\frac{\left(E_{t}^{f} / E_{t}^{m}\right)-1}{\left(E_{t}^{f} / E_{t}^{m}\right)+2\left(l^{f} / d^{f}\right)}$

$\eta_{t}=\frac{\left(E_{t}^{f} / E_{t}^{m}\right)-1}{\left(E_{t}^{f} / E_{t}^{m}\right)+2}$

Where $I^{f}$ and $d^{f}$ are the length and the diameter of the ONF.

Using $E_{t}^{f}$ obtained with Tsai-Pagano model and Halpin-Tsai equations, new values of $\eta_{o}, \eta_{l}$, $\eta_{e}$ and $\alpha$ can be calculated with the same equations used with the intrinsic Young's modulus obtained from Hirsch model.

\section{Results and discussion}

\subsection{Macro mechanics}

Table 1 shows the experimental data obtained from the stress-strain test of the ONF-PP composites, and morphological characterization of the fibers.

\section{TABLE 1}

It was found that the Young's modulus of the composite materials, increased linearly with the percentage of reinforcement, this was the expected behavior, considering a good fiber dispersion inside the matrix [27, 42]. By using ONF as reinforcing element, the rigidity of the plain matrix increased up to 3.5 times, in composites including $50 \mathrm{wt} \%$ of fiber content.

Rowell et al. [48] sorted cellulosic fillers/fibers under three categories, depending on their performance when incorporated in a plastic matrix. Strands were found the most efficient reinforcements, followed by wood fibers and wood flours. Table 2 shows the Young's modulus of PP composite materials reinforced with: ONF, hemp strands (HS) [26, 43], stone groundwood (SGW) [2] and E fiberglass (GF) [2].

\section{TABLE 2}


Composite materials reinforced with GF showed the highest increases in their Young's modulus, while HS were found to be the most efficient natural fibers in order to stiffen composite materials. Lopez et al. [2] studied Young's modulus of stone groundwood (virgin fibers mechanical pulp)-PP composites, and given that recycled newspaper was mainly composed of hardwood, it makes sense to compare the results. Young's moduli of ONF-PP composites were found to be slightly higher than those of SGW-PP composites and equivalent to $30 \%$ GF-PP composites.

The preparation of the composites and its injection resulted in a reduction of the fiber lengths $[26,39]$. The diminution of the fiber lengths could be caused by the attrition happening during the composite fabrication [49-51]. This is more relevant for coupled composites as the fiber is better tied to the matrix [52]. The average diameters of the fibers changed very little, so it was considered practically constant at a value of $21.6 \mu \mathrm{m}[8]$.

\subsection{Micro mechanics}

Manufactures are mainly interested in obtaining clear and reliable data on the materials mechanical characteristics, and in reducing the cost of the methods need to measure them [53]. When developing a new product, engineers and designers need guidance on the stiffening and reinforcing capabilities of different fibers, in order to formulate composite materials. Therefore, a fiber tensile modulus factor (FTMF) was tested as a candidate. The

value of FTMF $=\eta_{e} \cdot E_{t}^{f}$ (Eq. 3) shows the influence of the reinforcement on the Young's modulus of the composite, which is determined by the slope of linear tendency of graphs in Fig. 1. As it uses $\eta_{e}$, the proposed FTMF can be directly evaluated from the data obtained in the stress-strain test without further manipulation of the composite.

\section{FIGURE 1}

In this case the FTMF for ONF / PP composite was 11.32. The FTMF value obtained from SGW / PP composites [2] was 10.33, very similar to MP from ONF. On the other hand, the FTMF of GF / PP composites was evaluated to be 32.67 [2], 2.9 times higher than ONF 
composites. The FTMF of the reinforcements showed their correlation with the stiffening capabilities of the reinforcements. Once the FTMF for a specific matrix, reinforcement and manufacturing equipment is known, it could be compared with other materials to find the best candidate material for certain stiffness specifications.

\subsection{Micromechanics}

Table 3 shows computed values of the intrinsic modulus, obtained by means of Hirsch model, the efficiency factors and the mean orientation angle. Hirsch model and that modified rule of mixtures use exclusively experimental data to solve the fiber's intrinsic Young's modulus and the efficiency factor. Mean intrinsic Young's modulus of ONF was determined to be $22.8 \pm 1.8$ a value similar to that obtained in a previous work $21.2 \pm 1.9 \mathrm{GPa}$ [8]. Although there is a slight difference falls within the experimental error. The values were close to 18.2 $\pm 1.1 \mathrm{GPa}$ for stone groundwood fibers found by Lopez et al [52]. The value of the intrinsic Young's moduli of GF and HS computed by Hirsch method were found to be $76 \mathrm{GPa}$ [2] and $26.8 \mathrm{GPa}[26,43]$ respectively.

\section{TABLE 3}

Afterwards, the mROM (Eq.2) was applied to find the value of the efficiency factors. In this case, efficiency factors were found between 0.45 and 0.52 . In previous researches $[2,26$, $42,43]$ it was found that usually the value of efficiency factor was between 0.45 and 0.56 . Mean efficiency factor for the modulus, $0.49 \pm 0.04$ was inferior to that of SGW-PP composites, $0.56[2]$.

Hirsch model, FTMF and the rule of mixtures allowed calculating the intrinsic modulus of the fibers, the magnitude of the fiber's reinforcement contributions, and the efficiency factor. All the calculations were made form experimental data providing from tensile tests. Since the access to this kind of test is relatively easy we defined the process until that point as industry-friendly. To continue with the study, and solve Cox-Krenchel's model, it was 
necessary to extract the fibers from the composite and morphologically analyze them. Companies do not usually have such easy access to such methods.

Efficiency factor encloses the effects of the fiber length and orientation distributions $\left(\eta_{e}=\eta_{o}\right.$

- $\eta_{l}$ ). Consequently, in order to determine the influence of the distributions in the rule of mixtures, $\eta_{0}$ and $\eta_{1}$ were calculated (table 3 ). Length efficiency factor evolved linearly with the mean length values and with the aspect ratio (table 1). Orientation efficiency factors ranged from 0.5 to 0.57 , with a mean efficiency factor of $0.53 \pm 0.04$, corresponding to $52.5^{\circ} \pm 3.6$ mean fiber orientation angle, by using the square packing equation approximation (Eq. 6). The value of the mean orientation angle of the reinforcement into the composite, obtained from the calculus of the tensile strength [8] was $39.9^{\circ}$, a value $12^{\circ}$ lower to that of SGW-PP composites[2].

Lopez et al. [2] compared Young's moduli of coupled SGW-PP composites with moduli computed by means of Tsai-Pagano model and Halpin-Tsai equations and found a notable similariry. Tsai-Pagano model (Eq. 7) and Halpin-Tsai equations (Eq. 8, 9, 10 and 11) account for the fiber aspect ratio, therefore it was necessary to know mean length and mean diameter of the fibers to render results, making that model less industry-friendly, due to reasons discussed above. Anyhow they were used to compute the value of the intrinsic Young modulus of ONF, from that value the efficiency factors and the orientation angle were found (table 4).

\section{TABLE 4}

Mean intrinsic Young's modulus computed by Tsai-Pagano model and Halpin-Tsai equations was $22.7 \pm 2.7 \mathrm{GPa}, 0.1 \mathrm{GPa}$ lower than the former and 1.3 GPa higher that the proposed by Serrano et al. [8]. Although there is a difference, when the standard deviations are taken into account, the results are equal. Corresponding mean efficiency factor was $0.54 \pm 0.4$ almost identical to that calculated by means of Hirsch model. That's also true in the case of the mean fiber orientation angles, with a $0.1^{\circ}$ difference. While the values obtained from 
Hirsch model and from Halpin-Tsai equations for ONF-PP composites were almost equal, a slight difference was expected [2,52]. The difference shows the slight effect of the use of implicit aspect ratios in Halpin-Tsai equations in the final values. It also showed that, when experimental values of the Young's modulus of the composite were used to back calculate the intrinsic modulus of the fibers, the aspect ratio was explicitly incorporated in the Hirsch model.

The results showed the possibility of obtaining correct values form the stress-strain tests. Fig 2 shows the proposed diagram to back calculate macro and micro mechanics characteristics.

\section{FIGURE 2}

\section{Conclusions}

Old newspaper fibers showed potential as stiffening agent for polypropylene composites, with the possibility to substitute 20 to $30 \%$ fiberglass-PP composites by 40 to $50 \%$ ONF-PP composites. This involves a reduction on the use of synthetic polymers, avoiding fiberglass, and exploits the environmentally friendly character of natural fibers.

The fiber tensile modulus factor showed its potential as an easy way of measuring the fiber contribution to the composite modulus.

Hirsch model showed its usefulness to back calculate the intrinsic Young's moduli of short fibers from experimental data, when the direct measurement is nearly impossible. The mean intrinsic Young's moduli of ONF fibers was defined and found to be $21.2 \pm 1.9 \mathrm{GPa}$.

Hirsch model and the modified rule of mixtures showed their industry-friendly character as were capable of solving the macro and micromechanical characteristics of the composite materials from experimental data providing from stress-strain tests.Tsai-Pagano model and 
Halpin-Tsai equations showed also competency. The mean intrinsic Young's moduli of ONF fibers were defined and found to be $22.5 \pm 2.7 \mathrm{GPa}$.

The proposed method showed its industry-friendly character as it was capable of rendering correct results from experimental data obtained from tensile tests.

\section{References}

[1] Julian F, Mendez JA, Espinach FX, Verdaguer N, Mutje P, Vilaseca F. Bio-based composites from stone groundwood applied to new product development. BioResources. 2012;7:5829-42.

[2] Lopez JP, Mutje P, Pelach MA, El Mansouri NE, Boufi S, Vilaseca F. Analysis of the tensile modulus of PP composites reinforced with Stone grounwood fibers from softwood. BioResources. 2012;7:1310-23.

[3] Pere Lopez J, Girones J, Alberto Mendez J, El Mansouri N-E, Llop M, Mutje P, et al. Stone-ground wood pulp-reinforced polypropylene composites: water uptake and thermal properties. BioResources. 2012;7:5478-87.

[4] Ayrilmis N, Kaymakci A. Fast growing biomass as reinforcing filler in thermoplastic composites: Paulownia elongata wood. Industrial Crops and Products. 2013;43:457-64.

[5] Akil HM, Omar MF, Mazuki AAM, Safiee S, Ishak ZAM, Abu Bakar A. Kenaf fiber reinforced composites: A review. Materials \& Design. 2011;32:4107-21.

[6] Dehghani A, Madadi Ardekani S, Al-Maadeed MA, Hassan A, Wahit MU. Mechanical and thermal properties of date palm leaf fiber reinforced recycled poly (ethylene terephthalate) composites. Materials \& Design. 2013;52:841-8.

[7] Osman H, Ismail H, Mariatti M. Comparison of Reinforcing Efficiency between Recycled Newspaper (RNP)/Carbon Black (CB) and Recycled Newspaper (RNP)/Silica Hybrid Filled 
Polypropylene (PP)/Natural Rubber (NR) Composites. Journal of Reinforced Plastics and Composites. 2010;29:60-75.

[8] Serrano A, Espinach FX, Julian F, del Rey R, Mendez JA, Mutje P. Estimation of the interfacial shears strength, orientation factor and mean equivalent intrinsic tensile strength in old newspaper fiber / polypropylene composites. Composites Part B: Engineering. 2013:2328.

[9] Corbiere-Nicollier T, Gfeller-Laban B, Lundquist L, Leterrier Y, Manson JAE, Jolliet O. Life cycle assessment of biofibres replacing glass fibres as reinforcement in plastics. Resources Conservation and Recycling. 2001;33:267-87.

[10] Sanadi AR, Young RA, Clemons C, Rowell RM. Recycled newspaper fibers as reinforcing fillers in thermoplastic: 1 analysis of tensile and impact properties in polypropylene Journal of Reinforced Plastics and Composites. 1994;13:54-67.

[11] Pelach MA, Pastor FJ, Puig J, Vilaseca F, Mutje P. Enzymic deinking of old newspapers with cellulase. Process Biochem. 2003;38:1063-7.

[12] Flandez J, González I, Resplandis JB, El Mansouri N-E, Vilaseca F, Mutjé P. Management of corn stalk waste as reinforcement for polypropylene injection moulded composites. BioResources. 2012;2:1836-49.

[13] Franco-Marques E, Mendez JA, Pelach MA, Vilaseca F, Bayer J, Mutje P. Influence of coupling agents in the preparation of polypropylene composites reinforced with recycled fibers. Chemical Engineering Journal. 2011;166:1170-8.

[14] Girones J, Pimenta MTB, Vilaseca F, Carvalho AJF, Mutje P, Curvelo AAS. Blocked diisocyanates as reactive coupling agents: Application to pine fiber-polypropylene composites. Carbohydrate Polymers. 2008;74:106-13. 
[15] Vilaseca F, Mendez JA, Lopez JP, Vallejos ME, Barbera L, Pelach MA, et al. Recovered and recycled Kraft fibers as reinforcement of PP composites. Chemical Engineering Journal. 2008;138:586-95.

[16] Mendez JA, Vilaseca F, Pelach MA, Lopez JP, Barbera L, Turon X, et al. Evaluation of the reinforcing effect of ground wood pulp in the preparation of polypropylene-based composites coupled with maleic anhydride grafted polypropylene. J Appl Polym Sci. 2007;105:3588-96.

[17] Girones J, Mendez JA, Boufi S, Vilaseca F, Mutje P. Effect of silane coupling agents on the properties of pine fibers/polypropylene composites. J Appl Polym Sci. 2007;103:3706-17.

[18] Lopez JP, Mendez JA, Espinach FX, Julian F, Mutje P, Vilaseca F. Tensile Strength characteristics of Polypropylene composites reinforced with Stone Groundwood fibers from Softwood. BioResources. 2012;7:3188-200.

[19] Kuo P-Y, Wang S-Y, Chen J-H, Hsueh H-C, Tsai M-J. Effects of material compositions on the mechanical properties of wood-plastic composites manufactured by injection molding. Materials \& Design. 2009;30:3489-96.

[20] Sain M, Suhara P, Law S, Bouilloux A. Interface modification and mechanical properties of natural fiber-polyolefin composite products. Journal of Reinforced Plastics and Composites. 2005;24:121-30.

[21] Beg MDH, Pickering KL. Reprocessing of wood fibre reinforced polypropylene composites. Part I: Effects on physical and mechanical properties. Composites Part aApplied Science and Manufacturing. 2008;39:1091-100.

[22] Majeed K, Jawaid M, Hassan A, Abu Bakar A, Abdul Khalil HPS, Salema AA, et al. Potential materials for food packaging from nanoclay/natural fibres filled hybrid composites. Materials \& Design. 2013;46:391-410. 
[23] Neagu RC, Gamstedt EK, Berthold F. Stiffness contribution of various wood fibers to composite materials. Journal of Composite Materials. 2006;40:663-99.

[24] Dittenber DB, GangaRao HVS. Critical review of recent publications on use of natural composites in infrastructure. Composites Part a-Applied Science and Manufacturing. 2012;43:1419-29.

[25] Sanadi AR, Caulfield DF. Transcrystalline interphases in natural fiber-PP composites: effect of coupling agent. Composite Interfaces. 2000;7:31-43.

[26] Vallejos ME, Espinach FX, Julian F, Torres L, Vilaseca F, Mutje P. Micromechanics of hemp strands in polypropylene composites. Composites Science and Technology. 2012;72:1209-13.

[27] Thomason JL. The influence of fibre properties on the properties of glass-fibrereinforced polyamide 6,6. Journal of Composite Materials. 2000;34:158-72.

[28] Hirsch T. Modulus of elasticity of concrete affected by elastic moduli of cement paste matrix and aggregate. Journal of American Concrete Institute. 1962;59:427-51.

[29] Halpin JC. Stiffness and expansion estimates for oriented Short Fiber Composites. Journal of Composite Materials. 1969;3:732-\&.

[30] Halpin JC, Pagano NJ. The Laminate Approximation for Randomly Oriented Fibrous Composites. Journal of Composite Materials. 1969;3:720-4.

[31] Halpin JC, Tsai sW. Effects of environmental factors on composite materials. technical report AFML-TR-67-423. In: Laboratory AFM, editor. Ohio1969.

[32] Cox HL. The Elasticity and Strength of Paper and other Fibrous materials. British Journal of Applied Physics. 1952;3:72-9.

[33] Krenchel H. Fibre reinforcement. Copenhagen: Akademisk Forlag; 1964. 
[34] Rodriguez M, Rodriguez A, Bayer R J, Vilaseca F, Girones J, Mutje P. Determination of corn stalk fibers' strength through modeling of the mechanical properties of its composites. BioResources. 2010;5:2535-46.

[35] ASTM Standard D638-10, Standard Test Method for Tensile Properties of Plastics. ASTM International; 2010.

[36] ISO 1183-1, Plastics -- Methods for determining the density of non-cellular plastics -Part 1: Immersion method, liquid pyknometer method and titration method. International Organization for Standardization; 2012.

[37] Beckermann GW, Pickering KL. Engineering and evaluation of hemp fibre reinforced polypropylene composites: Micro-mechanics and strength prediction modelling. Composites Part A-Applied Science and Manufacturing. 2009;40:210-7.

[38] Hashemi S. Tensile and flexural properties of injection-moulded short glass fibre and glass bead ABS composites in the presence of weldlines. J Mater Sci. 2008;43:721-31.

[39] Li Y, Pickering KL, Farrell RL. Determination of interfacial shear strength of white rot fungi treated hemp fibre reinforced polypropylene. Composites Science and Technology. 2009;69:1165-71.

[40] Dhakal HN, Zhang ZY, Richardson MOW. Effect of water absorption on the mechanical properties of hemp fibre reinforced unsaturated polyester composites. Composites Science and Technology. 2007;67:1674-83.

[41] Kalaprasad G, Joseph K, Thomas S, Pavithran C. Theoretical modelling of tensile properties of short sisal fibre-reinforced low-density polyethylene composites. J Mater Sci. 1997;32:4261-7. 
[42] Vilaseca F, Valadez-Gonzalez A, Herrera-Franco PJ, Pelach MA, Lopez JP, Mutje P. Biocomposites from abaca strands and polypropylene. Part I: Evaluation of the tensile properties. Bioresource Technology. 2010;101:387-95.

[43] Espinach FX, Julian F, Verdaguer N, Torres L, Pelach MA, Vilaseca F, et al. Analysis of tensile and flexural modulus in hemp strands/polypropylene composites. Compos Pt B-Eng. 2013;47:339-43.

[44] Li Y, Mai YW, Ye L. Sisal fibre and its composites: a review of recent developments. Composites Science and Technology. 2000;60:2037-55.

[45] Virk AS, Hall W, Summerscales J. Modulus and strength prediction for natural fibre composites. Materials Science and Technology. 2012;28:864-71.

[46] Fukuda H, Kawata K. On Young's modulus of short fibre composites. Fibre Science and Technology. 1974;7:207-22.

[47] Thomason JL. The influence of fibre length and concentration on the properties of glass fibre reinforced polypropylene: 5. Injection moulded long and short fibre PP. Composites Part a-Applied Science and Manufacturing. 2002;33:1641-52.

[48] Rowell RM, Sanadi AR, Caulfield DF, Jacobson RE. Utilization of Natural Fibres in Plastic Composites: Problems and Opportunities. In: Leao AL, Carvalho FX, Frollini E, editors. Lignocellulosic-Plastics Composites. Sao Paulo (Brazil): Universidade de Sao Paulo, Universidade Estadual Paulista; 1997.

[49] Pegoretti A, DellaVolpe C, Detassis M, Migliaresi C, Wagner HD. Thermomechanical behaviour of interfacial region in carbon fibre/epoxy composites. Composites Part a-Applied Science and Manufacturing. 1996;27:1067-74.

[50] Mittal RK, Gupta VB, Sharma P. The effect of fibre orientation on the interfacial shear stress in short fibre - reinforced polypropylene. J Mater Sci. 1987:1949-55. 
[51] Karmaker AC, Youngquist JA. Injection molding of polypropylene reinforced with short jute fibers. J Appl Polym Sci. 1996;62:1147-51.

[52] Lopez JP, Mendez JA, El Mansouri NE, Mutje P, Vilaseca F. Mean intrinsic tensile properties of stone groundwood fibers from softwood. BioResources. 2011;6:5037-49.

[53] Thomason JL. Interfacial strength in thermoplastic composites - at last an industry friendly measurement method? Composites Part a-Applied Science and Manufacturing. 2002;33:1283-8. 
Figure Captions

Figure 1: Flexural tensile modulus factor for GF, ONF and SGW reinforced PP composites.

Figure 2: Macro and micromechanic properties proposed flowchart 
Figure 1

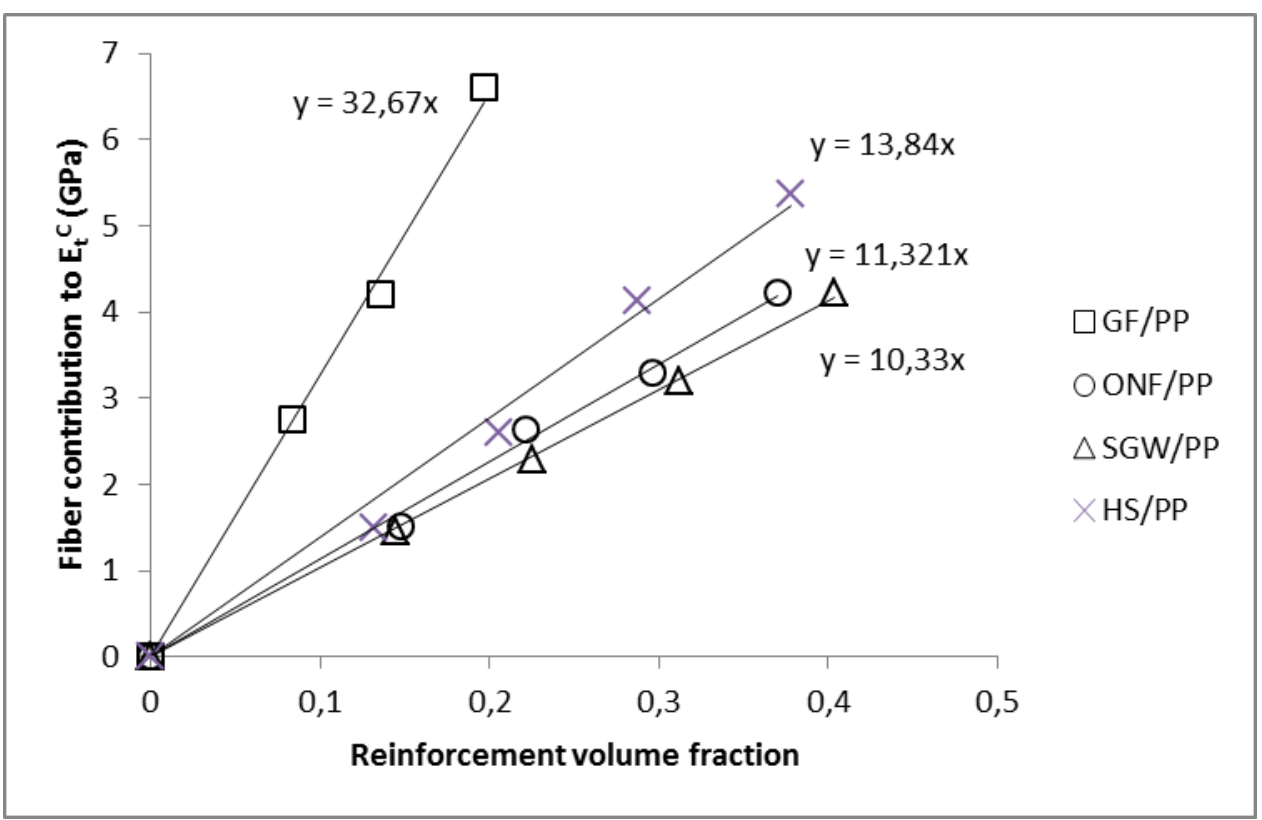


Figure 2

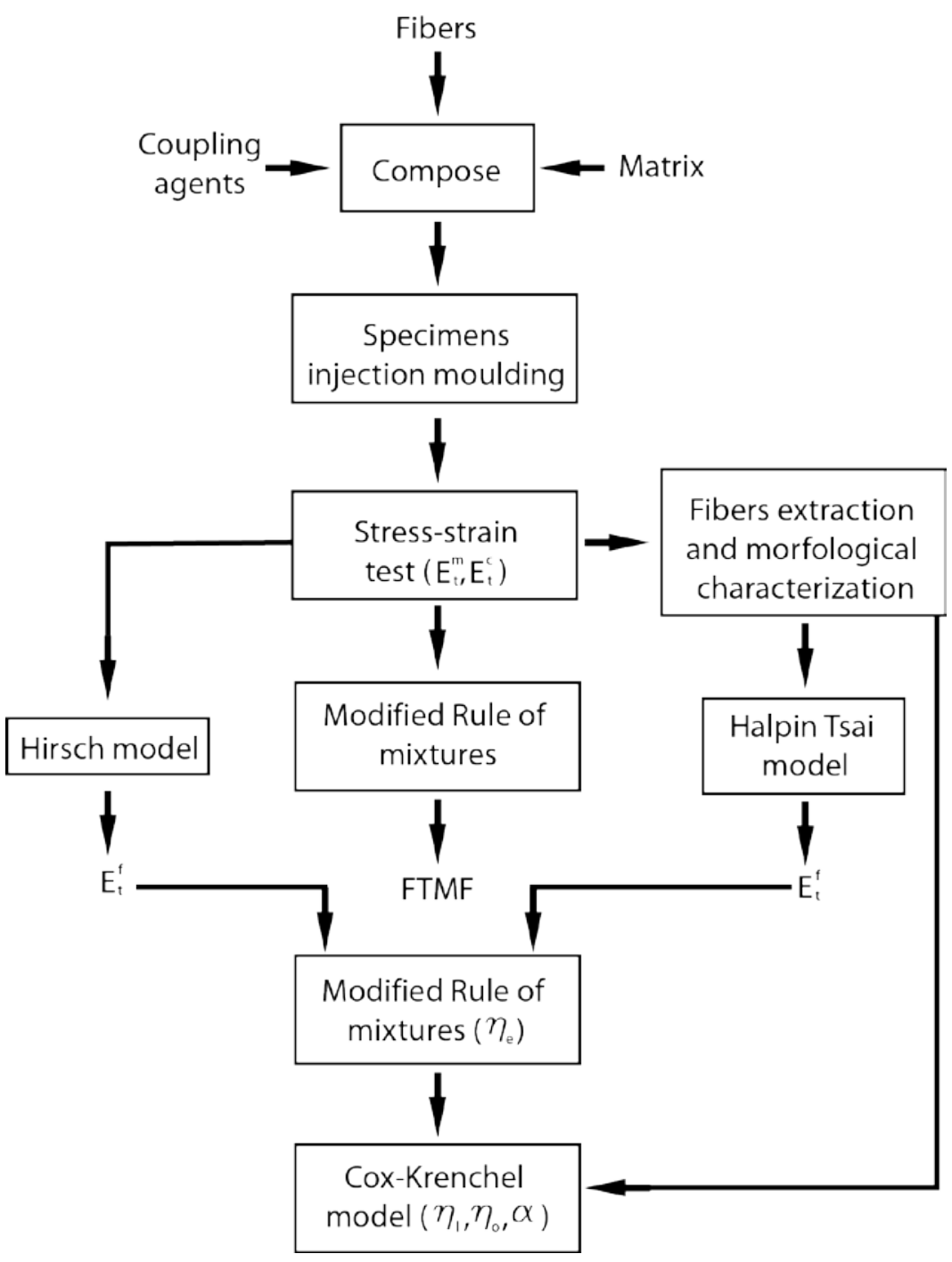


Table 1: Experimental values for 20 to 50\% coupled ONF-PP composites.

\begin{tabular}{ccccccc}
\hline $\begin{array}{c}\text { ONF content } \\
(\mathrm{wt} \%)\end{array}$ & $\begin{array}{c}\boldsymbol{V}^{t} \\
(\%)\end{array}$ & $\begin{array}{c}\boldsymbol{E}_{t}{ }^{\boldsymbol{m}} \\
(\mathrm{GPa})\end{array}$ & $\begin{array}{c}\boldsymbol{E}_{t}^{\boldsymbol{c}} \\
(\mathrm{GPa})\end{array}$ & $\begin{array}{c}\boldsymbol{I}^{t} \\
(\mu \mathrm{m})\end{array}$ & $\begin{array}{c}\boldsymbol{d}^{t} \\
(\mu \mathrm{m})\end{array}$ & $\boldsymbol{I}^{t} / \boldsymbol{d}^{t}$ \\
\hline 20 & 0.148 & $1.5 \pm 0.1$ & $2.8 \pm 0.1$ & 794 & 21.6 & 36.7 \\
\hline 30 & 0.222 & $1.5 \pm 0.1$ & $3.8 \pm 0.1$ & 664 & 21.6 & 30.7 \\
\hline 40 & 0.296 & $1.5 \pm 0.1$ & $4.2 \pm 0.1$ & 526 & 21.6 & 24.3 \\
\hline 50 & 0.370 & $1.5 \pm 0.1$ & $5.3 \pm 0.2$ & 416 & 21.6 & 19.2 \\
\hline
\end{tabular}

Table 2: Young's moduli of different composite materials (values in GPa).

\begin{tabular}{ccccc}
\hline $\begin{array}{c}\text { Fiber } \\
\text { content } \\
\text { (wt\%) }\end{array}$ & ONF & HS & SGW & GF \\
\hline 20 & $2.8 \pm 0.1$ & $2.8 \pm 0.1$ & $2.7 \pm 0.1$ & $4.1 \pm 0.1$ \\
\hline 30 & $3.8 \pm 0.1$ & $3.8 \pm 0.1$ & $3.4 \pm 0.05$ & $5.7 \pm 0.1$ \\
\hline 40 & $4.2 \pm 0.1$ & $5.2 \pm 0.2$ & $4.3 \pm 0.1$ & $7.7 \pm 0.1$ \\
\hline 50 & $5.3 \pm 02$ & $6.3 \pm 0.25$ & $5.2 \pm 0.1$ & - \\
\hline
\end{tabular}

Table 3: Intrinsic Young's moduli, obtained using Hirsch model, and micromechanic properties of ONF inside 20 to 50\% ONF-PP composites.

\begin{tabular}{cccccc}
\hline $\begin{array}{c}\text { ONF content } \\
(\mathrm{wt} \%)\end{array}$ & $\begin{array}{c}\boldsymbol{E}_{t}{ }^{\prime} \\
(\mathrm{GPa})\end{array}$ & $\eta_{e}$ & $\eta_{l}$ & $\eta_{o}$ & $\alpha$ \\
\hline 20 & 21.1 & 0.45 & 0.93 & 0.49 & 56.5 \\
\hline 30 & 24.7 & 0.52 & 0.92 & 0.56 & $49.9^{\circ}$ \\
\hline 40 & 21.4 & 0.47 & 0.91 & 0.51 & $54.5^{\circ}$ \\
\hline 50 & 23.9 & 0.52 & 0.90 & 0.57 & $49.5 .0^{\circ}$ \\
\hline
\end{tabular}

Table 4: Intrinsic Young's moduli, obtained using Halpin-Tsai equations, and micromechanic properties of ONF inside 20 to 50\% ONF-PP composites.

\begin{tabular}{cccccc}
\hline $\begin{array}{c}\text { ONF content } \\
(\mathrm{wt} \%)\end{array}$ & $\begin{array}{c}\boldsymbol{E}_{t}{ }^{+} \\
(\mathrm{GPa})\end{array}$ & $\eta_{e}$ & $\eta_{l}$ & $\eta_{0}$ & $\alpha$ \\
\hline 20 & 20.4 & 0.45 & 0.92 & 0.49 & $56.4^{\circ}$ \\
\hline 30 & 25.3 & 0.52 & 0.92 & 0.57 & $49.8^{\circ}$ \\
\hline 40 & 20.8 & 0.47 & 0.92 & 0.51 & $54.4^{\circ}$ \\
\hline 50 & 24.3 & 0.52 & 0.90 & 0.57 & $49.2^{\circ}$ \\
\hline
\end{tabular}

